\title{
Jobless Recoveries or Jobless Growth?
}

\author{
Adrian Peralta-Alva, Senior Economist
}

A s noted by many commentators, recent economic recoveries from recessions have been "jobless." A

jobless recovery occurs when output growth during a recovery remains steady but employment lags behind and takes longer to recover than in previous cycles. Since the 1990s, several authors have suggested structural factors may underlie this phenomenon. ${ }^{1}$ The evidence presented here suggests jobless recoveries since 2000 may be attributed to a slowdown in the long-term, or secular, employment trend-employment appears to grow at a slower pace since 2000. Given this trend, it is natural to expect that after a recession employment will take a relatively longer period to recover to its pre-recession levels. Recent experience suggests the U.S. economy has moved to a regime of jobless growth.

The first chart displays the U.S. employment-topopulation ratio from 1965-2010 and an extrapolated linear trend of the ratio (gray line) based on 1965 to 2000 data. The ratio increased almost 10 percentage points over the period. Most of this increase can be attributed to the entrance of women into the labor force. Starting in 2000, employment began to lag behind what the extrapolated linear trend would imply²: By 2006, the ratio was 3 per- centage points below the noted trend even though economic activity peaked during that year.

When compared with the first chart, the second chart shows how employment has behaved differently from gross domestic product (GDP). GDP does not deviate much from its trend, except after the most recent crisis. Economic growth since 2000 seems to be jobless indeed.

\section{Jobless recoveries since 2000 may be attributed to a slowdown in the long-term employment trend.}

The employment-to-population ratio stopped increasing around 2000. Since this ratio must be between 0 and 1 by definition, such an event is not completely surprising. This decrease in the ratio can account for a large part of the recent slowdown in employment and, therefore, for the jobless feature of recent recoveries. The "jobless" qualifier has been attached to recessions at least since 1991, which seems odd given the data shown here. My analysis illus-

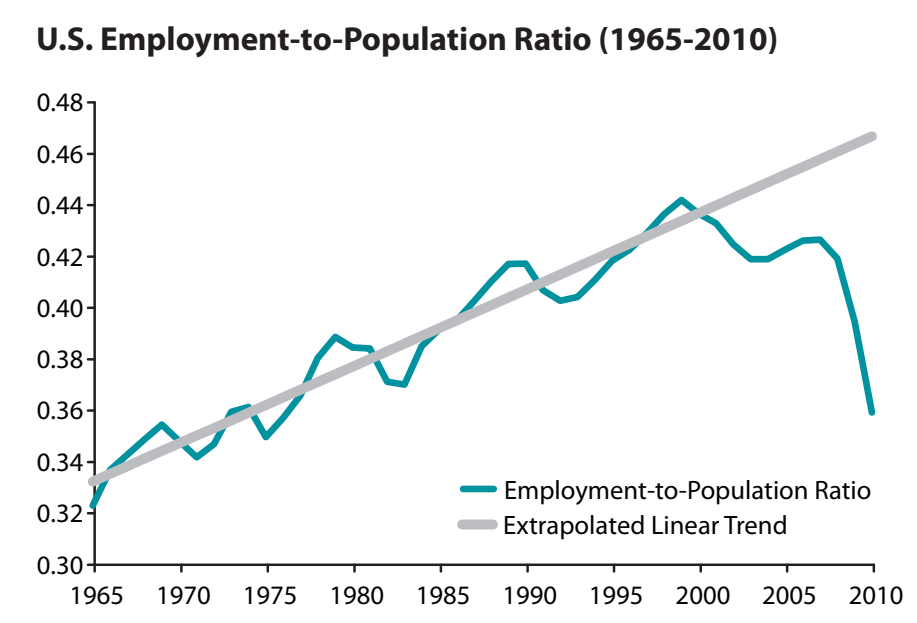

NOTE: The trend is based on 1965-2000 data.

\section{U.S. GDP (1965-2010)}

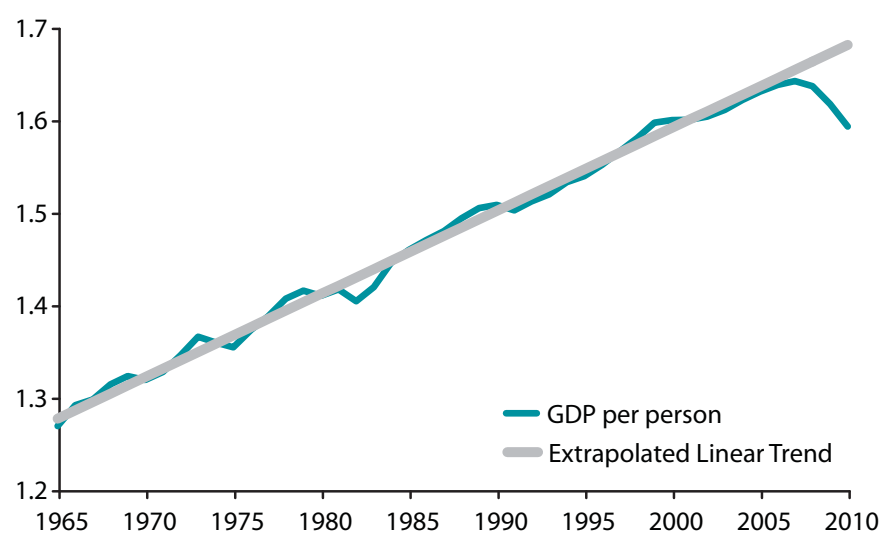

NOTE: The trend is based on 1965-2000 data. 
trates that, if the 1991 recession had occurred after 2000, it would have been much deeper than it actually was. Further research is needed to gain a better understanding of the patterns of economic and employment growth and their consequences.
${ }^{1}$ For example, see the following: Aaronson, Daniel; Rissman, Ellen R. and Sullivan, Daniel G. "Assessing the Jobless Recovery." Federal Reserve Bank of Chicago Economic Perspectives, 2nd Quarter 2004, 28(2), pp. 2-21;

www.chicagofed.org/digital_assets/publications/economic_perspectives/2004/ ep 2\%20Qtr \%202004 Part 1.pdf. Groshen, Erica L. and Potter, Simon. "Has Structural Change Contributed to a Jobless Recovery?" Federal Reserve Bank of New York Current Issues in Economics and Finance, August 2003, 9(8),

pp. 1-7; www.newyorkfed.org/research/current_issues/ci9-8.html.

2 I alternatively evaluated the Hodrick-Prescott trend of the data over the full sample period. This methodology resulted in the same qualitative conclusion (namely, a slowdown in the Hodrick-Prescott trend), so I used linear trends, which are easier to understand. 